\title{
Ultrasound assessment in psoriatic arthritis (PsA) and psoriasis vulgaris (non-PsA): which sites are most commonly involved and what features are more important in PsA?
}

\author{
Yuanjiao Tang, Shan Cheng, Yujia Yang, Xi Xiang, Liyun Wang, Lingyan Zhang, Li Qiu \\ Department of Ultrasound, West China Hospital of Sichuan University, Chengdu 610041, China \\ Correspondence to: Li Qiu, MD. Department of Ultrasound, West China Hospital of Sichuan University, No.37 Guo Xue Xiang, Chengdu 610041, \\ China. Email: wsqiuli@126.com.
}

\begin{abstract}
Background: The aim of this study was to find out the most commonly involved sites and the most important ultrasonic features in psoriatic arthritis (PsA).

Methods: In total, 120 PsA patients and 320 psoriasis vulgaris (non-PsA) patients were assessed by grayscale and power Doppler (PD) ultrasound (US). Joints, tendons, enthesis, and bursa changes were observed. Weights of affected anatomical sites of PsA patients (overall weights $>90 \%$ ) were calculated. Affected anatomical sites between PsA and non-PsA patients were compared. Ultrasonic features of joint, tendon, entheses, and bursa changes between PsA and non-PsA patients were also compared. Finally, the test performance of ultrasonic features for the diagnosis of PsA was calculated.

Results: The anatomical sites with the highest weights were the Achilles tendon, quadriceps tendon, and knee; weights of these anatomical sites were all more than 5\%. Among the affected anatomical sites of PsA patients, most of the anatomical sites were more greatly affected in the PsA patients than in the nonPsA patients (all $\mathrm{P}<0.05$ ). The comparison of the affected Achilles tendon, quadriceps tendon, MTP1, subacromial-subdeltoid bursa, MCP4, and MCP3 showed no significance between PsA and non-PsA patients (all $\mathrm{P}>0.05$ ). Joint synovial thickening, joint PD signal grades, joint bone erosions, tendon sheath synovial thickening, tendon sheath PD signals, enthesis bone erosions, and enthesis PD signals in PsA patients were higher than in non-PsA patients (all $\mathrm{P}<0.05$ ). Joint $\mathrm{PD}$ signal grades, joint bone erosions, enthesis bone erosions, and enthesis PD signals showed the highest specificities, which were $96.06 \%, 95.15 \%, 96.93 \%$, and $94.63 \%$ respectively.

Conclusions: The most common involvement sites of PsA were the Achilles tendon, quadriceps tendon, and knee, and some sites in non-PsA patients were also highly involved. The most important features in PsA included joint PD signal grades, joint bone erosion, entheses bone erosions, and entheses PD signals in US assessment.
\end{abstract}

Keywords: Ultrasound assessment (US assessment); psoriatic arthritis (PsA); involved sites; ultrasonic features

Submitted May 23, 2019. Accepted for publication Aug 09, 2019.

doi: 10.21037/qims.2019.08.09

View this article at: http://dx.doi.org/10.21037/qims.2019.08.09

\section{Introduction}

Psoriatic arthritis (PsA) is a chronic inflammatory joint disease associated with psoriasis, which is deforming and destructive in $40-60 \%$ of patients and entails consequent functional impairment, decreased quality of life, psychosocial disability, and an increased risk of death $(1,2)$. It is a heterogeneous disease with different domains and particular sites involved. Its heterogeneity is such that the term "psoriatic disease" has been suggested to encompass involvement at many different tissue levels, including joints, 
entheses, tendon, bursae, skin, and nails $(3,4)$.

Not only has it been demonstrated that ultrasound (US) is more sensitive than radiography, but it is also more sensitive than clinical examination for the assessment of inflammatory and structural changes in inflammatory arthritis, including PsA, and particularly synovitis, enthesitis, tenosynovitis, and bursitis (5-7). US results are comparable to those of magnetic resonance imaging (MRI), except for bone marrow edema detection. The reproducibility and low cost of the US provide advantages over MRI for PsA detection (8-10). The current European League Against Rheumatism (EULAR) recommendations favor the use of US in rheumatoid arthritis (RA). In routine practice and clinical trials of PsA, disease activity is still monitored by RA-specific clinical composite scores. These measures, however, are of questionable value for PsA because of the heterogeneous nature of the disease characterized by various joint, enthesis, tendon, and bursa features (11-13). Therefore, a dedicated US examination is needed to monitor disease activity and progression of PsA.

However, a complete US examination of all joints, entheses, tendons, and bursae that can be affected in PsA would be extremely time consuming and infeasible. Also, there is no current agreement on the optimal number or the specific sites which should be assessed for a sensitive and feasible US assessment (14). Furthermore, which ultrasonic features are most important are still unknown. The aim of this study was to find out the most common involvement sites of joints, entheses, tendons, and bursae by ultrasonography and discover the most important ultrasonic features in PsA, which are of great value in daily US practice.

\section{Methods}

\section{Patient population}

This cross-sectional study comprised 120 PsA patients and 320 psoriasis vulgaris (non-PsA) patients aged $\geq 18$ years old at the Department of Ultrasound in West China Hospital, Sichuan University. All patients were examinated by US from January 2016 to July 2018. It was approved by the ethics committee of West China Hospital, Sichuan University. Before they had the US, all subjects were provided with informed consent that explained that their imaging data would be used for scientific research. The inclusion criteria for the PsA patients were consistent with the Classification Criteria for Psoriasis-Arthritis. Exclusion criteria were as follows: (I) pregnancy; (II) a recent history of trauma; (III) engagement of heavy manual labor; (IV) a history of any other form of arthritis; and (V) current or recent ( $\leq 3$ months) systemic treatment for psoriasis. The inclusion criterion for the non-PsA patients was diagnosed pathologically based on skin biopsy by a dermatologist. Exclusion criteria were as follows: (I) pregnancy; (II) a recent history of trauma; (III) engagement of heavy manual work; (IV) PsA diagnosis or a history of other forms of arthritis; and (V) current or recent ( $\leq 3$ months) systemic treatment for psoriasis.

\section{US examination}

Grayscale and power Doppler (PD) US (Philips IU22) were used to assessing the changes of joints, entheses, tendons, and bursae in each subject. The probe frequency was set at 3-9 or 5-12 MHz, and the musculoskeletal condition was selected. The gain was set at maximum sensitivity without noise signals. The joints scanned included the shoulders, elbows, wrists, hips, knees, ankles, tarsal joints, metacarpophalangeal joints, metatarsophalangeal joints, and interphalangeal joints of the fingers and toes. The anterior and posterior recesses of the shoulders, radial, coronoid and posterior recesses of the elbows, anterior recesses of the hips, suprapatellar, medial and lateral recesses of the knees, and the anterior and lateral recesses of the ankles were scanned; the metacarpophalangeal joints and interphalangeal joints of the fingers were dorsally and palmarly scanned; and the tarsal joints, metatarsophalangeal joints, and interphalangeal joints of the toes were dorsally scanned. The tendons scanned included the long heads of the biceps brachii, flexor and extensor tendons of the hands and feet, anterior tibialis tendon, posterior tibialis tendon, and the peroneal tendon and tendon sheaths. The entheses scanned included the common flexor and extensor entheses of the hands, quadriceps, gluteus medius, gluteus minimus, proximal and distal patellar, Achilles, and plantar aponeurosis entheses. The bursae scanned included the retrocalcaneal, subacromial-subdeltoid, olecranal, and gastrocnemius-semimembranosus bursae. All tendons, entheses, and bursae underwent transverse and longitudinal complete scanning.

As for the joints, joint effusion, synovial thickening, osteophytes, and bone erosions were evaluated (Figure 1A). The joint PD signals were scored as follows: grade 0 (no intraarticular color signals), grade 1 ( $\leq 3$ color signals), grade $2(<50 \%$ of the intraarticular area filled with color 

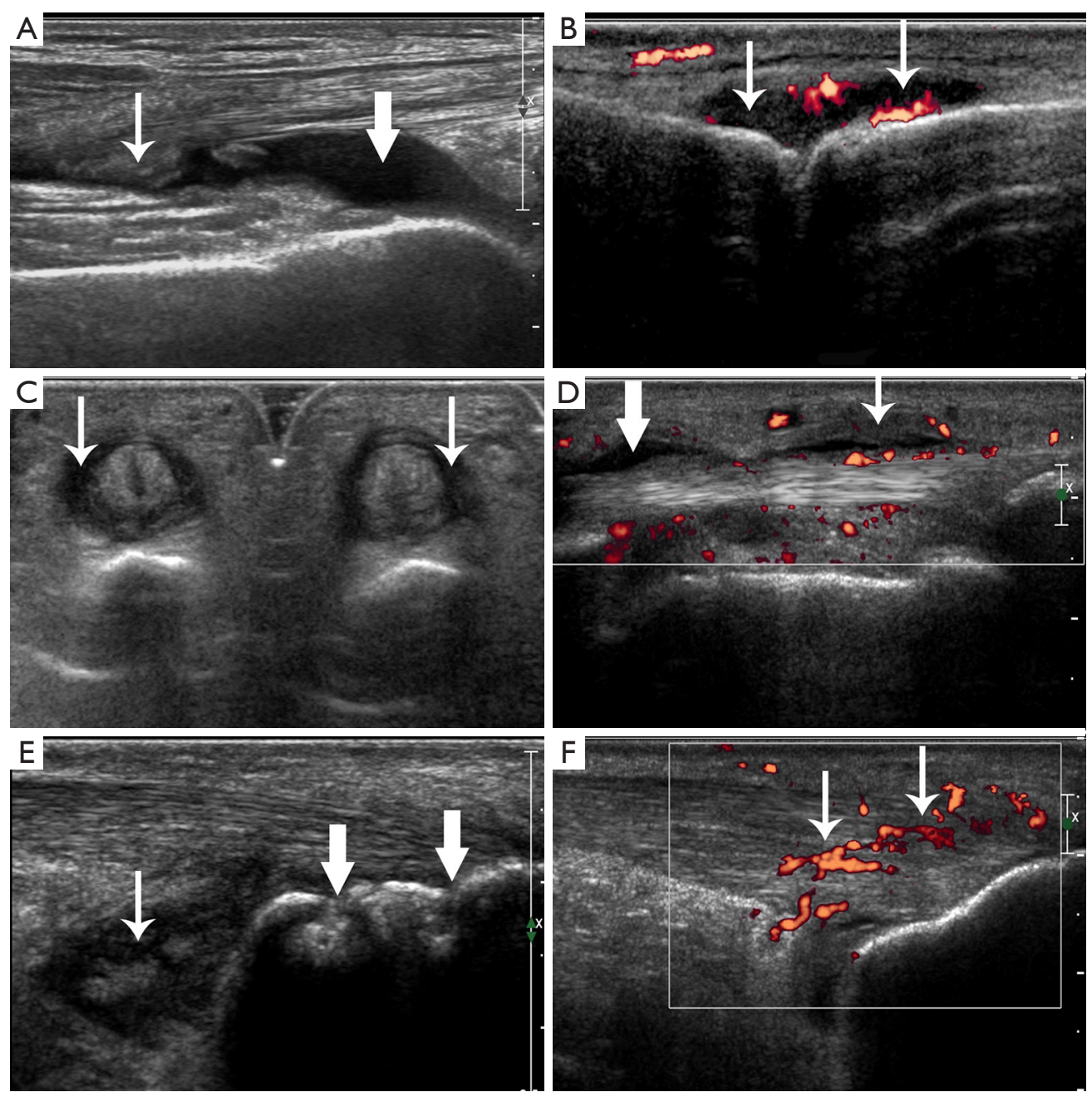

Figure 1 Ultrasonic appearances of joint, tendon, enthesis, and bursa changes. (A) Joint effusion (crude arrow) and synovial thickening (fine arrow) in a left knee in a non-PsA patient. (B) Joint synovial thickening with PD signals of grade 2 (arrows) in a right metacarpophalangeal joint in a PsA patient. (C) Tendon sheath synovial thickening (arrows) in digital flexor tendons of a left hand in a PsA patient. (D) Tendon sheath effusion (crude arrow) and tendon sheath synovial thickening with PD signals (fine arrow) in a digital flexor tendon of a right hand in a PsA patient. (E) Enthesis bone erosion (crude arrows) in a left Achilles tendon and bursa synovial thickening (fine arrow) in the retrocalcaneal bursae in a PsA patient. (F) Enthesis thickening, hypoechogenicity with PD signals (arrows) in a right Achilles tendon in a PsA patient. PsA, psoriatic arthritis; PD, power Doppler.

signals, Figure 1B), grade 3 (>50\% of the intraarticular area filled with color signals) (15). For the tendons, we assessed tendon thickening, tendon hypoechogenicity, tendon PD signals, tendon sheath effusion, tendon sheath synovial thickening, and tendon sheath PD signals (Figure 1C,D). For the entheses, we evaluated enthesis thickening, hypoechogenicity, calcifications, enthesophytes, bone erosions, and PD signals (Figure 1E,F). For the bursae, we estimated bursa effusion, synovial thickening, and PD signals (Figure 1E).
US scan was performed by 2 adept radiologists with 7 and 10 years' experience in musculoskeletal US imaging. The scanning time was about 30 to $60 \mathrm{~min}$ per individual. The imaging experts were blinded to patient data; all patients underwent the US in random order and were instructed not to communicate with the sonographer about their disease during the US assessment. Before the study, the investigators reached a consensus on the US scanning technique and method of data interpretation to adopt. A diagnostic consistency test was conducted, and a 
Table 1 Patient characteristics

\begin{tabular}{lccc}
\hline Variables & $\begin{array}{c}\text { Non-PsA } \\
(n=320)\end{array}$ & PsA $(n=120)$ & $P$ \\
\hline Age, yrs, range & $18-78$ & $18-70$ & - \\
Age, yrs & $39.88 \pm 13.21$ & $40.74 \pm 11.50>0.05$ \\
Male, \% & 66.56 & 67.50 & $>0.05$ \\
BMl, kg/m² & $23.76 \pm 3.14$ & $23.57 \pm 3.00>0.05$ \\
Psoriasis duration, yrs, range & $0.17-41$ & $0.5-35$ & - \\
Psoriasis duration, yrs & $11.24 \pm 9.06$ & $11.92 \pm 7.71$ & $>0.05$ \\
\hline
\end{tabular}

Values are mean \pm SD unless otherwise specified. PsA, psoriatic arthritis; BMI, body mass index.

$\kappa$ value of 0.85 was obtained. Briefly, the above-mentioned joints, entheses, tendons, and bursae of the 10 PsA patients were evaluated by the two radiologists. Grayscale and PD changes of these joints, entheses, tendons, and bursae were observed.

Weights of affected anatomical sites of PsA patients (overall weights $>90 \%$ ) were calculated. Weights were calculated as products of the numbers of affected anatomical sites divided by the total number of affected anatomical sites and normalized to $0-100 \%$. Affected anatomical sites between the PsA and non-PsA patients were compared. Ultrasonic features of joint, tendon, entheses, and bursa changes between the PsA and non-PsA patients were also compared. Finally, the test performance of ultrasonic features for the diagnosis of PsA was calculated.

\section{Statistical analysis}

The SPSS 22.0 (SPSS Inc.) software was used for data analysis, with $\mathrm{P}<0.05$ considered statistically significant. Measurement data were compared by independent sample t-test. Enumeration data were compared by the Pearson chi-square test or Fisher's exact test. Ranked data were assessed by the Mann-Whitney $\mathrm{U}$ test.

\section{Results}

\section{Patient characteristics}

Our current study included 120 PsA patients and 320 nonPsA patients. The main characteristics of the study patients are shown in Table 1. Age, sex distribution, body mass index (BMI), and duration of psoriasis in PsA and non-PsA patients showed no significant difference (all $\mathrm{P}>0.05$ ).
Weights of affected anatomical sites of Ps A patients (overall weights $>\mathbf{9 0} \%$ )

Weights of affected anatomical sites of PsA patients (overall weights $>90 \%$ ) were reported in Figure 2. The anatomical sites with higher weights were the Achilles tendon, quadriceps tendon, knee, first metatarsophalangeal joint (MTP1), wrist, MTP2, ankle, plantar aponeurosis, MTP3, flexor tendon of the hand, third proximal interphalangeal joint (PIP3) of the hand, first interphalangeal joint (IP1) of the toe, second metacarpophalangeal joint (MCP2), IP1 of the hand, MCP1, and MCP5. Weights of these anatomical sites were all more than $2 \%$. Furthermore, the Achilles tendon, quadriceps tendon, and knee achieved the highest weights, which were all more than $5 \%$.

\section{Comparison of affected anatomical sites between Ps $A$ and non-Ps $A$ patients}

Among the affected anatomical sites of PsA patients (overall weights $>90 \%$ ), most of the anatomical sites were more affected in PsA patients than in non-PsA patients, which included the knee, wrist, MTP2, ankle, plantar aponeurosis, MTP3, flexor tendon of the hand, PIP3 of the hand, IP1 of the toe, MCP2, IP1 of the hand, MCP1, MCP5, shoulder, PIP2 of the hand, MTP4, third distal interphalangeal joint (DIP3) of the hand, posterior tibialis tendon, DIP2 of the hand, PIP4 of the hand, tendon of the long heads of biceps brachii, distal insertion of the patellar tendon, elbow, PIP5 of the hand, MTP5, PIP2 of the toe, PIP4 of the toe, retrocalcaneal bursa, extensor tendon of the hand, and proximal insertion of the patellar tendon (all $\mathrm{P}<0.05$; Table 2). However, the comparison of the affected achilles tendon, quadriceps tendon, MTP1, subacromial-subdeltoid bursa, MCP4, and MCP3 showed no significance between PsA and non-PsA patients (all $\mathrm{P}>0.05$; Table 2).

\section{Comparison of ultrasonic features between PsA and non- PsA patients}

The results are summarized in Table 3.

\section{Joint changes}

In total, 942 joints were affected in PsA patients, while 990 were affected in non-PsA patients. Joint effusion in nonPsA patients was significantly higher than in PsA patients $(\mathrm{P}<0.05)$. Joint synovial thickening, $\mathrm{PD}$ signal grades, and bone erosions in PsA patients were significantly higher than 


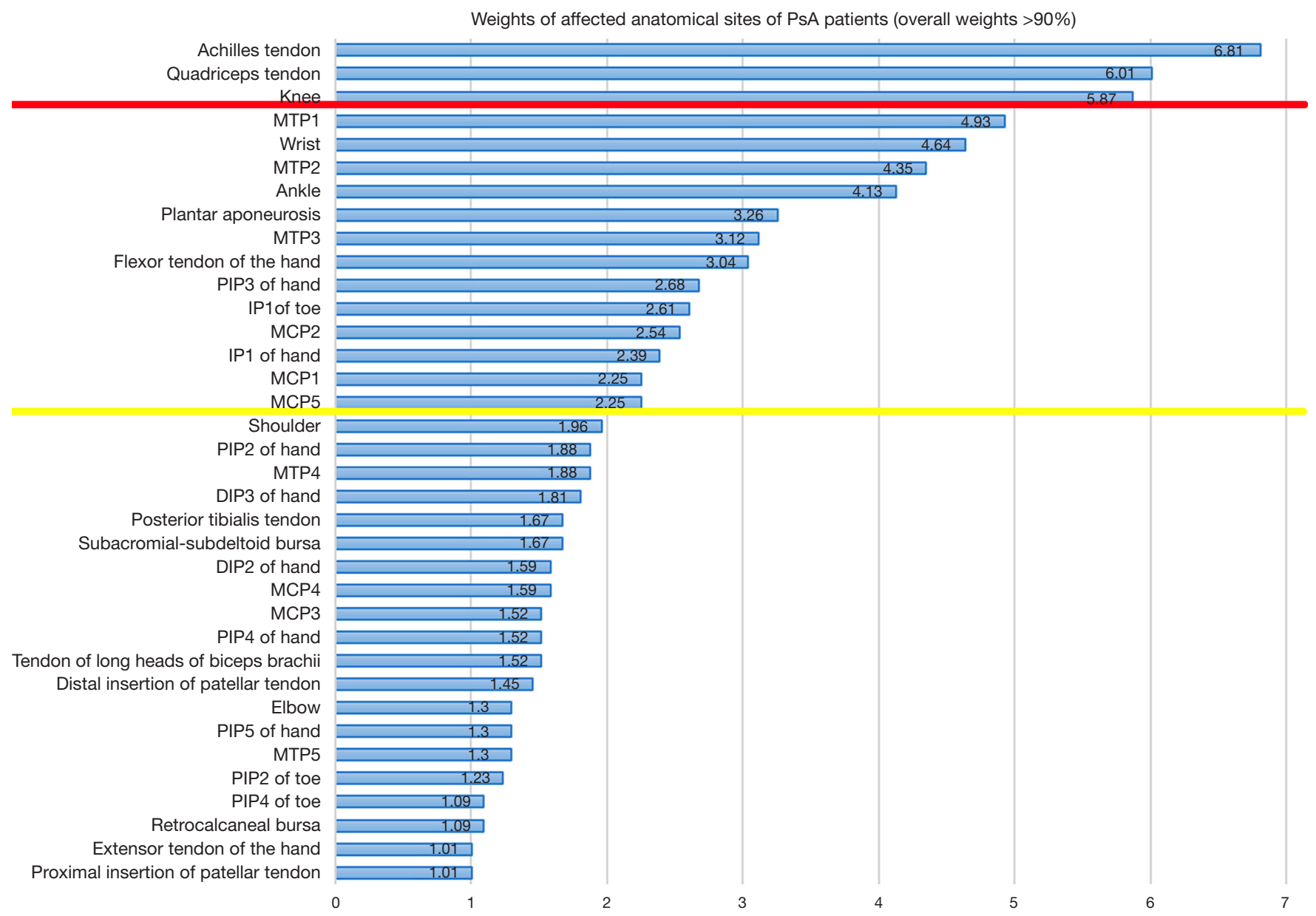

Figure 2 Weights of affected anatomical sites of PsA patients (over weights $>90 \%$ ). PsA, psoriatic arthritis.

in non-PsA patients (all $\mathrm{P}<0.05$ ). However, the difference in joint osteophytes between these two groups showed no significance $(\mathrm{P}>0.05)$.

\section{Tendon changes}

In total, 116 tendons were affected in PsA patients, while 64 were affected by non-PsA patients. Tendon sheath effusion in non-PsA patients was significantly higher than in $\mathrm{PsA}$ patients $(\mathrm{P}<0.05)$. Tendon sheath synovial thickening and tendon sheath PD signals in PsA patients were greater than in non-PsA patients, with the differences being significant (both $\mathrm{P}<0.05$ ). Nevertheless, differences of tendon thickening, tendon hypoechogenicity, and tendon PD signals between these two groups showed no significance (all $\mathrm{P}>0.05$ ).

\section{Entheses changes}

In total, 267 entheses were affected in PsA patients, while
521 were affected in non-PsA patients. Enthesophytes in non-PsA patients were significantly higher than in PsA patients $(\mathrm{P}<0.05)$. Entheses bone erosions and $\mathrm{PD}$ signals in PsA patients were significantly higher than in nonPsA patients (both $\mathrm{P}<0.05$ ). However, enthesis thickening, hypoechogenicity, and calcifications between PsA and nonPsA patients had no significant differences (all $\mathrm{P}>0.05$ ).

\section{Bursa changes}

In total, 39 bursa were affected in PsA patients, while 70 were affected in non-PsA patients. All ultrasonic features of bursa lesions (bursa effusion, bursa synovial thickening, and bursa PD signals) between PsA and non-PsA patients showed no significant differences (all $\mathrm{P}>0.05$ ).

Test performance of ultrasonic features for the diagnosis of Ps $A$

Based on the above results, we used ultrasonic features of 
Table 2 A comparison of affected anatomical sites between PsA and non-PsA patients (\%)

\begin{tabular}{|c|c|c|c|}
\hline Anatomical sites & $\begin{array}{c}\text { Non-PsA } \\
(n=640)\end{array}$ & $\begin{array}{c}\text { PsA } \\
(n=240)\end{array}$ & $\mathrm{P}$ \\
\hline Knee & 19.22 & 33.75 & 0.000 \\
\hline Wrist & 5.63 & 26.67 & 0.000 \\
\hline MTP2 & 10.00 & 25.00 & 0.000 \\
\hline Ankle & 8.44 & 23.75 & 0.000 \\
\hline Plantar aponeurosis & 7.97 & 18.75 & 0.000 \\
\hline MTP3 & 7.97 & 17.92 & 0.000 \\
\hline Flexor tendon of hand & 1.41 & 17.50 & 0.000 \\
\hline PIP3 of hand & 5.47 & 15.42 & 0.000 \\
\hline IP1 of hand & 0.63 & 13.75 & 0.000 \\
\hline MCP1 & 0.47 & 12.92 & 0.000 \\
\hline MCP5 & 5.47 & 12.92 & 0.000 \\
\hline Shoulder & 2.66 & 11.25 & 0.000 \\
\hline PIP2 of hand & 1.88 & 10.83 & 0.000 \\
\hline DIP3 of hand & 2.34 & 10.42 & 0.000 \\
\hline Posterior tibialis tendon & 2.34 & 9.58 & 0.000 \\
\hline DIP2 of hand & 2.34 & 9.17 & 0.000 \\
\hline PIP4 of hand & 2.66 & 8.75 & 0.000 \\
\hline PIP5 of hand & 0.63 & 7.50 & 0.000 \\
\hline MTP5 & 1.09 & 7.50 & 0.000 \\
\hline PIP2 of toe & 0.78 & 7.08 & 0.000 \\
\hline PIP4 of toe & 0.78 & 6.25 & 0.000 \\
\hline Extensor tendon of hand & 0.78 & 5.83 & 0.000 \\
\hline Proximal insertion of patellar tendon & 1.09 & 5.83 & 0.000 \\
\hline MCP2 & 7.03 & 14.58 & 0.001 \\
\hline Elbow & 2.34 & 7.50 & 0.001 \\
\hline IP1of toe & 7.81 & 15.00 & 0.002 \\
\hline Retrocalcaneal bursa & 2.66 & 6.25 & 0.015 \\
\hline Distal insertion of patellar tendon & 4.06 & 8.33 & 0.016 \\
\hline MTP4 & 5.94 & 10.83 & 0.019 \\
\hline $\begin{array}{l}\text { Tendon of long heads of biceps } \\
\text { brachii }\end{array}$ & 4.84 & 8.75 & 0.036 \\
\hline MCP4 & 5.63 & 9.17 & 0.067 \\
\hline Achilles tendon & 32.81 & 39.17 & 0.080 \\
\hline MCP3 & 6.09 & 8.75 & 0.177 \\
\hline Subacromial-subdeltoid bursa & 6.88 & 9.58 & 0.199 \\
\hline Quadriceps tendon & 31.09 & 34.58 & 0.331 \\
\hline MTP1 & 29.84 & 28.33 & 0.679 \\
\hline
\end{tabular}

PsA, psoriatic arthritis; MTP, metatarsophalangeal; PIP, proximal interphalangeal; IP, interphalangeal; MCP, metacarpophalangeal; DIP, distal interphalangeal.
Table 3 Ultrasonic features of joint, tendon, entheses and bursa changes/case (\%)

\begin{tabular}{|c|c|c|}
\hline Features & Non-PsA & PsA \\
\hline Features of joint changes & $\mathrm{n}=990$ & $\mathrm{n}=942$ \\
\hline Joint effusion & $485(48.99)^{\#}$ & $234(24.84)$ \\
\hline Joint synovial thickening & $447(45.15)$ & $636(67.51)^{\star}$ \\
\hline \multicolumn{3}{|l|}{ Joint PD signal grades } \\
\hline 0 & $951(96.06)$ & $734(77.92)^{\star}$ \\
\hline 1 & $29(2.93)$ & $98(10.40)$ \\
\hline 2 & $10(1.01)$ & $94(9.98)$ \\
\hline 3 & $0(0.00)$ & $16(1.70)$ \\
\hline Joint osteophytes & $136(13.74)$ & $101(10.72)$ \\
\hline Joint bone erosion & $48(4.85)$ & $226(23.99)^{*}$ \\
\hline Features of tendon changes & $\mathrm{n}=64$ & $n=116$ \\
\hline Tendon thickening & $1(1.56)$ & $6(5.17)$ \\
\hline Tendon hypoechogenicity & $1(1.56)$ & $6(5.17)$ \\
\hline Tendon PD signals & $1(1.56)$ & $3(2.59)$ \\
\hline Tendon sheath effusion & $49(76.56)^{\#}$ & $43(37.07)$ \\
\hline Tendon sheath synovial thickening & $20(31.25)$ & $91(78.45)^{*}$ \\
\hline Tendon sheaths PD signals & $9(14.06)$ & $53(45.69)^{\star}$ \\
\hline Features of entheses changes & $n=521$ & $n=267$ \\
\hline Entheses thickening & $186(35.70)$ & $110(41.20)$ \\
\hline Entheses hypoechogenicity & $172(33.01)$ & 105 (39.33) \\
\hline Entheses calcifications & $41(7.87)$ & $17(6.37)$ \\
\hline Enthesophytes & $418(80.23)^{\#}$ & $174(65.17)$ \\
\hline Entheses bone erosions & $16(3.07)$ & $41(15.36)^{*}$ \\
\hline Entheses PD signals & $28(5.37)$ & $44(16.48)^{*}$ \\
\hline Features of bursa changes & $n=70$ & $n=39$ \\
\hline Bursa effusion & $20(28.57)$ & $12(30.77)$ \\
\hline Bursa synovial thickening & $55(78.57)$ & 31 (79.49) \\
\hline Bursa PD signals & $3(4.29)$ & $6(15.38)$ \\
\hline
\end{tabular}

\#, $\mathrm{P}<0.05$ versus $\mathrm{PsA}$ group; ${ }^{*}, \mathrm{P}<0.05$ versus non-PsA group. PsA, psoriatic arthritis; PD, power Doppler.

joint synovial thickening, joint PD signal grades, joint bone erosions, tendon sheath synovial thickening, tendon sheath PD signals, enthesis bone erosions, and PD signals to diagnose PsA, the results of which are presented in Table 4. Ultrasonic features of joint PD signal grades, joint bone erosions, enthesis bone erosions, and enthesis PD signals 
Table 4 Test performance of ultrasonic features for the diagnosis of PsA

\begin{tabular}{|c|c|c|c|c|c|c|c|}
\hline Parameters & $\begin{array}{l}\text { Joint synovial } \\
\text { thickening }\end{array}$ & $\begin{array}{c}\text { Joint PD signal } \\
\text { grades }\end{array}$ & $\begin{array}{l}\text { Joint bone } \\
\text { erosion }\end{array}$ & $\begin{array}{c}\text { Tendon sheath } \\
\text { synovial thickening }\end{array}$ & $\begin{array}{c}\text { Tendon sheaths } \\
\text { PD signals }\end{array}$ & $\begin{array}{c}\text { Entheses bone } \\
\text { erosions }\end{array}$ & $\begin{array}{l}\text { Entheses } \\
\text { PD signals }\end{array}$ \\
\hline Sensitivity & $67.52 \%$ & $22.08 \%$ & $23.99 \%$ & $78.45 \%$ & $45.69 \%$ & $15.36 \%$ & $16.48 \%$ \\
\hline Positive likelihood ratio & 1.50 & 5.60 & 4.95 & 2.51 & 3.25 & 5.00 & 3.07 \\
\hline Negative predictive value & $63.96 \%$ & $56.44 \%$ & $56.82 \%$ & $63.77 \%$ & $46.61 \%$ & $69.08 \%$ & $68.85 \%$ \\
\hline
\end{tabular}

showed the highest specificities, which were $96.06 \%$, $95.15 \%, 96.93 \%$, and $94.63 \%$ respectively. Meanwhile, the ultrasonic features of tendon sheath synovial thickening had the highest sensitivity of $78.45 \%$.

\section{Discussion}

As we know, multiple joints, entheses, tendons, and bursae can be involved in the PsA of patients, but a complete US examination of all joints, entheses, tendons, and bursae in PsA would be extremely time consuming and infeasible. The aim of this study was to guide the use of US in PsA patients in daily clinical practice.

\section{The most commonly involved sites}

Our study demonstrated that the affected anatomical sites with higher weights included the Achilles tendon, quadriceps tendon, knee, MTP1, wrist, MTP2, ankle, plantar aponeurosis, MTP3, flexor tendon of the hand, PIP3 of the hand, IP1 of the toe, MCP2, IP1 of the hand, MCP1, and MCP5. Weights of these anatomical sites were all more than $2 \%$. The Achilles tendon, quadriceps tendon, and knee achieved the highest weights, which were all more than $5 \%$. Based on previous studies, the MCP joints, knee, Achilles tendon, plantar aponeurosis, and quadriceps tendon were commonly affected in PsA patients (9,16-18). Our results were consistent with the previous studies. One recent study showed that the Achilles tendon was the most commonly affected site in PsA patients, and the weight was $7 \%$ (19). Our study showed the same result, and the weight was $6.81 \%$. These results remind us that the above-mentioned anatomical structures, especially the Achilles tendon, quadriceps tendon, and knee should all be included and paid attention to when conducting the US on PsA patients in daily practice. Based on our study, the most commonly involved sites of PsA are the quadriceps tendon and knee in a similar way that the most common involvement sites of rheumatic arthritis are the wrist and proximal PIPs.

Among the affected anatomical sites of PsA patients (overall weights $>90 \%$ ), most of the anatomical sites were more greatly affected in PsA patients than in nonPsA patients, which could explain the poorer clinical manifestations of PsA patients who showed more pain, dyskinesia, dysfunction, and quality of life, compared with non-PsA patients. It is worth mentioning that the comparison of the affected Achilles tendon, quadriceps tendon, MTP1, subacromial-subdeltoid bursa, MCP4, and MCP3 showed no significance between PsA and non-PsA patients, though these sites were highly affected in PsA patients. The findings indicate that these sites were also highly involved in non-PsA patients. This suggests that non-PsA patients may have subclinical musculoskeletal involvement, which may predict the clinical onset of PsA, as proposed previously (20). Other supporting studies demonstrated that the prevalence of asymptomatic synovitis and enthesitis was significantly higher in non-PsA patients than in healthy controls $(10,20)$. Therefore, regular US screening is also necessary and important for non-PsA patients. As for the Achilles tendon, which was the most involved in PsA patients, it showed no difference between PsA and non-PsA patients. We speculate this was because PsA patients had higher enthesis bone erosions and enthesis PD signals than non-PsA patients, and non-PsA patients showed higher enthesophytes than PsA patients.

\section{Most important ultrasonic features}

Joint effusion, tendon sheath effusion, and enthesophytes 
were the most frequently seen ultrasonic feature in nonPsA patients, and these ultrasonic features in non-PsA patients all had significantly higher incidences than those in PsA patients (all $\mathrm{P}<0.05)$. As these ultrasonic features were not active and led to milder damage relatively, the results could explain why non-PsA patients had milder clinical manifestations and better prognosis.

Nevertheless, PsA patients were more likely to show joint synovial thickening, joint PD signal grades, joint bone erosions, tendon sheath synovial thickening, tendon sheath PD signals, enthesis bone erosions, and enthesis PD signals on the US. The incidences of these features in PsA patients were all higher than in non- PsA patients and the differences were significant $($ all $\mathrm{P}<0.05)$. This means that PsA patients had more serious joint, tendon, and enthesis damage, and more active inflammation. The results could explain why PsA patients had more severe clinical manifestations and worse prognosis. Our findings showed that, compared with non-PsA patients, PsA patients had more pain, dyskinesia, and dysfunction because of these features. Based on our test performance, joint PD signal grades, joint bone erosions, enthesis bone erosions, and enthesis PD signals showed the highest specificities, which were all more than $90 \%$. In other words, they are the most important ultrasonic features of PsA. This was similar to the results of previous studies which confirmed that bone erosions and PD signals of joints and entheses are indications of more severe manifestations and poorer outcomes $(4,21,22)$. In other words, more attention should be paid when PsA patients have joint PD signal grades, joint bone erosion, enthesis bone erosions, and enthesis PD signals in daily practice.

Meanwhile, ultrasonic features of joint osteophytes, tendon thickening, tendon hypoechogenicity, tendons PD signals, enthesis thickening, enthesis hypoechogenicity, enthesis calcifications, and all bursa lesions showed no significant differences between PsA and non-PsA patients. As indicated by our study, these features were relatively unimportant compared with the above-mentioned features of PsA. However, one recent study published by the Outcome Measures in Rheumatology (OMERACT) imaging group showed that the final agreed definition of a US-detected enthesitis in patients with PsA was the following: hypoechoic and/ or thickened insertion of the tendon close to the bone which exhibits Doppler signal if active and which may show erosions and enthesophytes/ calcifications as a sign of structural damage (23). However, this study did not compare PsA patients with non-PsA patients. Thus, further studies by US are needed in clinical trials and practice.

Our study has some limitations. First, other abnormalities of PsA, such as dactylitis and nail changes, were not assessed despite the good sensitivity of the US. Second, our study did not compare the findings of PsA with other arthritis, such as rheumatic arthritis or osteoarthritis. These limitations should be addressed in future studies.

\section{Conclusions}

The most common involvement sites of PsA were the Achilles tendon, quadriceps tendon, and knee, and some sites in the non-PsA patients were also highly involved. The most important features in PsA included joint PD signal grades, joint bone erosions, enthesis bone erosions, and enthesis PD signals in US assessment.

\section{Acknowledgments}

Funding: This study was supported by the National Natural Science Foundation of China (81671696) and Science and Technology Support Program of Sichuan Province, China (2019YFS0444).

\section{Footnote}

Conflicts of Interest: The authors have no conflicts of interest to declare.

Ethical Statement: The study was approved by the West China Hospital of Sichuan University Ethics Committee. Informed consent was obtained from all volunteers.

\section{References}

1. Cozzi F, Raffeiner B, Beltrame V, Ciprian L, Coran A, Botsios C, Perissinotto E, Grisan E, Ramonda R, Oliviero F, Stramare R, Punzi L. Effects of mud-bath therapy in psoriatic arthritis patients treated with TNF inhibitors. Clinical evaluation and assessment of synovial inflammation by contrast-enhanced ultrasound (CEUS). Joint Bone Spine 2015;82:104-8.

2. McHugh NJ, Balachrishnan C, Jones SM. Progression of peripheral joint disease in psoriatic arthritis: a $5-y r$ prospective study. Rheumatology (Oxford) 2003;42:778-83.

3. Ritchlin CT. From skin to bone: translational perspectives on psoriatic disease. J Rheumatol 2008;35:1434-7.

4. Grassi W, Gutierrez M. Psoriatic Arthritis: Need for 
Ultrasound in Everyday Clinical Practice. J Rheumatol Suppl 2012;89:39-43.

5. Wiell C, Szkudlarek M, Hasselquist M, Møller JM, Vestergaard A, Nørregaard J, Terslev L, Østergaard M. Ultrasonography, magnetic resonance imaging, radiography, and clinical assessment of inflammatory and destructive changes in fingers and toes of patients with psoriatic arthritis. Arthritis Res Ther 2007;9:R119.

6. Weiner SM, Jurenz S, Uhl M, Lange-Nolde A, Warnatz K, Peter HH, Walker UA. Ultrasonography in the assessment of peripheral joint involvement in psoriatic arthritis: a comparison with radiography, MRI and scintigraphy. Clin Rheumatol 2008;27:983-9.

7. Dougados M, Jousse-Joulin S, Mistretta F, d'Agostino MA, Backhaus M, Bentin J, Chalès G, Chary-Valckenaere I, Conaghan P, Etchepare F, Gaudin P, Grassi W, van der Heijde D, Sellam J, Naredo E, Szkudlarek M, Wakefield $\mathrm{R}$, Saraux A. Evaluation of several ultrasonography scoring systems for synovitis and comparison to clinical examination: results from a prospective multicentre study of rheumatoid arthritis. Ann Rheum Dis 2010;69:828-33.

8. Taljanovic MS, Melville DM, Gimber LH, Scalcione LR, Miller MD, Kwoh CK, Klauser AS. High-resolution US of rheumatologic diseases. Radiographics 2015;35:2026-48.

9. Coates LC, Hodgson R, Conaghan PG, Freeston JE. MRI and ultrasonography for diagnosis and monitoring of psoriatic arthritis. Best Pract Res Clin Rheumatol 2012;26:805-22.

10. Tang Y, Yang Y, Xiang X, Wang L, Zhang L, Qiu L. Power Doppler Ultrasound Evaluation of Peripheral Joint, Entheses, Tendon, and Bursa Abnormalities in Psoriatic Patients: A Clinical Study. J Rheumatol 2018;45:811-7.

11. Smolen JS, Braun J, Dougados M, Emery P, Fitzgerald O, Helliwell P, Kavanaugh A, Kvien TK, Landewé R, Luger T, Mease P, Olivieri I, Reveille J, Ritchlin C, Rudwaleit M, Schoels M, Sieper J, Wit Md, Baraliakos $\mathrm{X}$, Betteridge N, Burgos-Vargas R, Collantes-Estevez E, Deodhar A, Elewaut D, Gossec L, Jongkees M, Maccarone M, Redlich K, van den Bosch F, Wei JC, Winthrop K, van der Heijde D. Treating spondyloarthritis, including ankylosing spondylitis and psoriatic arthritis, to target: recommendations of an international task force. Ann Rheum Dis 2014;73:6-16.

12. Anandarajah AP, Ritchlin CT. The diagnosis and treatment of early psoriatic arthritis. Nat Rev Rheumatol 2009;5:634-41.

13. Ficjan A, Husic R, Gretler J, Lackner A, Graninger WB, Gutierrez M, Duftner C, Hermann J, Dejaco
C. Ultrasound composite scores for the assessment of inflammatory and structural pathologies in Psoriatic Arthritis (PsASon-Score). Arthritis Res Ther 2014;16:476.

14. Mandl P, Naredo E, Wakefield RJ, Conaghan PG, D'Agostino MA; OMERACT Ultrasound Task Force. A systematic literature review analysis of ultrasound joint count and scoring systems to assess synovitis in rheumatoid arthritis according to the OMERACT filter. J Rheumatol 2011;38:2055-62.

15. Backhaus M, Ohrndorf S, Kellner H, Strunk J, Backhaus TM, Hartung W, Sattler H, Albrecht K, Kaufmann J, Becker K, Sörensen H, Meier L, Burmester GR, Schmidt WA. Evaluation of a novel 7-joint ultrasound score in daily rheumatologic practice: a pilot project. Arthritis Rheum 2009;61:1194-201.

16. Delle Sedie A, Riente L. Psoriatic arthritis: what ultrasound can provide us. Clin Exp Rheumatol 2015;33:S60-5.

17. Gutierrez M, Draghessi A, Bertolazzi C, Erre GL, Saldarriaga-Rivera LM, López-Reyes A, FernándezTorres J, Audisio MJ, Pineda C; Pan-American League Against Rheumatisms (PANLAR) Ultrasound Study Group. Ultrasound in psoriatic arthritis. Can it facilitate a best routine practice in the diagnosis and management of psoriatic arthritis? Clin Rheumatol 2015;34:1847-55.

18. Marchesoni A, Atzeni F, Spadaro A, Lubrano E, Provenzano G, Cauli A, Olivieri I, Melchiorre D, Salvarani C, Scarpa R, Sarzi-Puttini P, Montepaone M, Porru G, D'Angelo S, Catanoso M, Costa L, Manara M, Varisco V, Rotunno L, DE Lucia O, DE Marco G. Identification of the clinical features distinguishing psoriatic arthritis and fibromyalgia. J Rheumatol 2012;39:849-55.

19. Zabotti A, Piga M, Canzoni M, Sakellariou G, Iagnocco A, Scirè CA; UPSTREAM study group. Ultrasonography in psoriatic arthritis: which sites should we scan? Ann Rheum Dis 2018;77:1537-8.

20. Naredo E, Möller I, de Miguel E, Batlle-Gualda E, Acebes C, Brito E, Mayordomo L, Moragues C, Uson J, de Agustín JJ, Martínez A, Rejón E, Rodriguez A, Daudén E; Ultrasound School of the Spanish Society of Rheumatology and Spanish ECO-APs Group. High prevalence of ultrasonographic synovitis and enthesopathy in patients with psoriasis without psoriatic arthritis: a prospective case-control study. Rheumatology (Oxford) 2011;50:1838-48.

21. Anandarajah AP, El-Taha M, Peng C, Reed G, Greenberg JD, Ritchlin CT. Association between focal erosions and generalized bone loss in psoriatic arthritis. Ann Rheum 
Dis 2011;70:1345-7.

22. D'Agostino MA. Enthesitis detection by ultrasound: where are we now? Clin Exp Rheumatol 2018;36:127-30.

23. Balint PV, Terslev L, Aegerter P, Bruyn GAW, CharyValckenaere I, Gandjbakhch F, Iagnocco A, JousseJoulin S, Möller I, Naredo E, Schmidt WA, Wakefield

Cite this article as: Tang Y, Cheng S, Yang Y, Xiang X, Wang L, Zhang L, Qiu L. Ultrasound assessment in psoriatic arthritis (PsA) and psoriasis vulgaris (non-PsA): which sites are most commonly involved and what features are more important in PsA? Quant Imaging Med Surg 2020;10(1):86-95. doi: 10.21037/ qims.2019.08.09
RJ, D'Agostino MA; OMERACT Ultrasound Task Force members. Reliability of a consensus-based ultrasound definition and scoring for enthesitis in spondyloarthritis and psoriatic arthritis: an OMERACT US initiative. Ann Rheum Dis 2018;77:1730-5. 